\title{
Quality assurance program of a nuclear facility
}

\author{
Dmitriy Leybman and Tatiana Khripko* \\ Moscow State University of Civil Engineering, Yaroslavskoe shosse, 26, Moscow, 129337, Russia
}

\begin{abstract}
Quality Assurance Program (QAP, Program) is a standard, which regulates and coordinates activity, as well as determines quality assurance policy regarding services rendered and construction works conducted on nuclear infrastructure facilities. The Program must comply with the requirements of federal rules and regulations in the field of nuclear power engineering. The present QAP is available to all organisation employees carrying out works and rendering services during construction, reconstruction and major repairs of nuclear facilities as well as to experts conducting works and rendering services on a contract basis. The QAP implementation analysis and the evaluation of its results is conducted through internal audits. The implementation of the quality assurance program is provided through the following principles:

- the responsibility for quality assurance when conducting actual works and rendering services is imposed upon the task performer;

- precise segregation of duties and responsibilities between all contractors;

- regular control of compliance with regulations and developer's requirements, as well as accurate documentation of the monitoring results;

- systematic update tracking for all official regulations and norms;

- the quality assurance methods incorporate the classification of equipment, systems and installation in terms of their impact on safety of nuclear facilities approved by official rules and regulations in the atomic energy sector.
\end{abstract}

\section{Introduction}

Quality management in the nuclear industry is of paramount importance, the solution of which affects not only individual intra-industry aspects of nuclear energy facilities, but also the environment, life and health of the population, the work of many enterprises and the economic performance of the region and the country as a whole. Any shortcomings affecting the quality of work at nuclear facilities and ensuring the safety of their operation can lead to serious consequences across the region and country. Timely diagnosis of processes, the establishment of critical values for these and other indicators, as well as the planning of operational response procedures for deviations $[1,2,4]$. The effectiveness of the QAP operation is subject to continuous monitoring, both from internal auditors and through external inspections. Control is carried out through special control and auditing measures designed to track the correct implementation of procedures and planned quality measures, to ensure compliance with the norms and regulations and the implementation of established goals. Quality assurance program - document (set of documents), which

*Corresponding author: tasha.pr@mail.ru 
establishes a set of organizational and technical and other quality assurance measures aimed at implementing the established criteria and to ensure plant safety principles. It should be noted that the development of one quality assurance program for several types of activity at one or several nuclear facilities should be justified in the appropriate quality assurance program. Similarly for a private organization, taking into account its own conditions and features. The quality assurance program must be approved and put into effect prior to the commencement of activities in the field of the use of atomic energy to which it applies [1120].

The priority of safety over other factors of scientific and technical activity is proclaimed by the leadership of the organization in the leadership (position, etc.) of the safety culture and communicated to the workers. The system of selection, vocational training and maintaining the qualifications of workers implemented in the organization is aimed at ensuring that the qualifications and readiness of employees meet the requirements, characteristics and production conditions, taking into account all the principles and elements of safety culture reflected in the safety manual, including leadership skills of managers at all levels administrative hierarchy. Assessing (self-assessing) safety culture is a prerequisite for effective planning of activities to build and maintain a safety culture[3]. The level of safety culture is determined by conducting audits (checks). Audits (inspections) are independent from the executors and their direct managers of the conformity assessment of activities and work performed to the requirements of quality assurance programs.

Reliability assurance of conducted work (rendered services) is achieved through:

- the use of verified and certified equipment and software (if necessary);

- division heads and specialists are authorized to perform the work (provide the service) upon passing certification procedure testified sufficient knowledge of norms and regulations in the sphere of atomic energy use;

- applying a quality control system;

- optimal organization of work execution (service delivery) processes;

- introduction of organizational and technical measures that morally and financially stimulate the provision of specified indicators of reliability and durability with minimal time and material costs;

- professional development of managers and specialists;

- high technical training of personnel and its periodic certification.

Design reliability is ensured by:

- the use of the necessary technical solutions in the design and objects of use of atomic energy (OIAE);

- the use of products and equipment with a sufficient level of reliability that meets the criterion of a single failure;

- maintainability of systems and equipment, timely implementation of outage;

- proper organization of the technological process;

- involvement of trained and certified personnel.

For equipment and components of systems important to safety, the requirements for the following reliability indicators are set at the design stage:

- reliability;

- maintainability;

- durability;

- persistence.

Provision:

- retaining measurement equipment in working condition;

- checking (calibration) of measurement equipment;

- registration and certification of testing equipment; 
- registration and certification of measurement algorithms;

- metrological assessment of documentation elaborated by the organization;

- metrological supervision of condition and use of measurement equipment, references, measurement algorithms, meeting the calibration deadlines.

Software and calculation algorithms used in construction of nuclear facilities are selected to meet the requirements of regulatory documents, are verified and certified (if necessary). Basic quality assurance procedures when using software and calculation algorithms in safety-crucial systems:

- use of only licensed (certified) software products and calculation algorithms;

- providing reliability of software scripts and calculation algorithms by conducting timely operational checks, timely correction of their working parameters, technical integrity of systems where the given software and calculation algorithms operate, enhancing redundancy of the software and calculation algorithms;

- conducting regular anti-virus control of software products;

- excluding unauthorized access to the software operating environment;

- minimizing the impact of unauthorized access to software products;

- administering of authorized access to software.

The control of compliance with the requirements for software by contractor- companies is carried out during checks of quality assurance program implementation and/or during scheduled checks (audits) [5-10].

\section{Methods}

The results of the quality assurance program is defined through audits (checks). Audits (checks) are independent from executive parties and their management evaluations of compliance of activity areas and conducted works with the QAP requirements.

Audits (checks) are conducted to:

- evaluate the implementation of the quality policy;

- provide regular systematic evaluation of quality assurance programs;

- provide implementation of all actions stipulated in QAP;

- estimate the considered activity in case there are complaints and reclamations in terms of quality of conducted works;

- control the implementation of corrective and preventing actions;

- evaluate quality assurance programs of organizations contracted for works, services by the operating organization;

- evaluate the implementation of duties and requirements by a contracting company in accordance with the contract and regulating documents.

A representative of the organization management is responsible for audits (checks) of quality assurance and for the control over their implementation.

Activities upon audit completion imply:

- analysis of revealed nonconformities, determining the reasons, as well required corrections to eliminate the nonconformities, corrective actions to eliminate the reasons and prevent their re-occurrence;

- check (random inspection) of implementation of corrective and preventive actions of the action plan and evaluation of their efficiency during next audit.

Organization and support of audits (checks) conducted by representatives of the client (operating company), a supervision authority, self-regulatory organizations (non commercial partnerships), by a certification authority implies:

- audit program consideration and preparation of an authorizing document about the organization of the audit (check); 
- implementation of events stipulated by the authorizing document about the organization of the audit (check);

- support of commission work that performs the audit (check);

- audit report consideration, discussion of results, discussion of commission work results, its conclusions and proposals;

- elaboration of measures aimed to eliminate the critical issues mentioned in the certificate (report) of the commission, bringing them to force by an enabling document of organization;

- implementation of actions to eliminate critical issues.

Activity upon completion of audits (checks) by supervision authorities stipulates consideration of revealed nonconformities and their analysis at the management level of audited divisions and provosts by areas of activity. Taken decisions get registered in the minutes of the related meetings and/or corrective action plans (in case there are nonconformities).

System condition evaluation includes:

- evaluation of program implementation efficiency;

- determining of forms and methods of learning the system assumptions, safety culture, conducting evaluation of training efficiency;

- consideration of reports of division heads on their activity, defining areas for further improvement;

- generating measures to enhance the safety culture of the organization;

- defining directions for quality system improvement in accordance with international norms, advanced practices, etc.

\section{Results}

Nonconformity management is applicable to all types of activities on construction of infrastructure facilities.

Nonconformities include, in particular:

- non-fulfilment or deviation from set requirements;

- incorrect or incomplete information provided in documentation;

- violation of requirements of regulatory documents by employees of involved companies;

- defects, failures and damages revealed during equipment acceptance, installation and finetuning works.

Nonconformity management implies:

- revealing, documentation, and registration of nonconformities;

- determining a probable reason for the nonconformity;

- notification about nonconformities;

- analysis aimed to reveal significant nonconformities, core reasons for nonconformities as well as contributing factors; - taking decision on nonconformity correction, elaboration and implementation of corrective actions to eliminate the revealed reasons for nonconformity and prevent reoccurrence;

- elaboration and implementation of preventive measures targeted at elimination of nonconformity reasons;

- nonconformity elimination, control over their elimination, documenting the process;

- control over decision implementation on nonconformities, evaluation of efficiency of corrective and preventive measures;

- information exchange (internal and external);

- control over activities of sub-contract organizations in terms of nonconformity management; 
- defining reason changing trends and the types of violations upon the nonconformity analysis.

Nonconformities may be revealed during:

- incoming inspection of project and contest documentation;

- control (incoming, operational) and technical supervision;

- designer supervision;

- acceptance control and testing's;

- acceptance of works and constructed objects;

- incoming control of equipment and materials;

- audits (checks);

- internal inspections;

- inspections by the client of public supervision authorities.

The revealed nonconformities are registered (recorded) in form set for all types of processes where they may occur. These forms of nonconformity records include:

- registers (general and specific, work logs, design supervision, etc.);

- equipment certificates and log-books;

- orders;

- certificates (incoming supervision, interim job completion, critical structures, building examination, etc.);

- reports (on audit completion, inspection results, etc.);

- orders (on audit results, etc.);

- minutes of the meetings.

Registration of nonconformities is the responsibility of personnel of:

- contracting (subcontracting) organizations - when conducting works;

- supervising services - when conducting acceptance commissions and tests, audits (checks) of quality assurance system, technological processes;

- supervising and regulatory bodies - when conducting audits (checks) in reports (certificates) upon audit completion.

Nonconformity management procedures define the duties and responsibilities of divisions and employees of participating companies.

The head of the company division where a nonconformity is revealed, analyses the situation to determine the core and direct reasons and elaborate adequate corrective (preventive) actions. The search for direct reasons includes analysis of all circumstances which led to occurrence and development of a nonconformity, as well as actions which preceded to it. The analysis result is the ground for making a decision on the nonconformity, for further actions in this regard (with classification of this nonconformity as a significant or non significant). A significant nonconformity has the following feature:

- a nonconformity which requires a report to be sent to a regulatory authority;

- a nonconformity which refers to regulatory requirements of license conditions;

- serious nonconformity in the quality system or suspension of corrective actions;

- a repetitive nonconformity where previous corrective actions turned out to be ineffective.

A significant nonconformity entails a research needed to determine its core reason. Core reasons of nonconformities lie in flaws of equipment in use, technical maintenance organization, personnel qualification.

When revealing and analyzing a core reason, there is conducted a check with the analysis of the documentation of organization (standards, guidelines, regulations, instructions, etc.) Corrective and preventing actions are elaborated to eliminate the reasons of nonconformity and prevent their re-occurrence, as well as to improve the acting quality assurance program. Corrective and preventive actions are normally arranged in a form of plan of actions brought into force by enabling documents (orders, decrees) which define all required organizational and technical arrangements. In order to provide control over the 
intended corrective and preventive actions, the enabling document contains responsible employees among the company's management. Based on the information about the results of applied corrective (preventive) actions, an analysis of their efficiency is conducted. The efficiency may be estimated by the degree of implementation of planned actions, the amplitude of used resources and compliance with deadlines of corrective (preventing) actions. These estimation results may be used as incoming data for the analysis of quality system functioning on the side of the company management, as well as for quality system improvement processes and improvement of the company's operations in general.

\section{Discussion}

Safety culture assembly of characteristics and attitudes in organizations and individuals which establishes that, as an overriding priority, protection and safety issues receive the attention warranted by their significance. Safety culture is an integral part of the culture of organizations performing engineering surveys, the preparation of project documentation and construction. The required level of safety culture is achieved both by the implementation of the security policy in the organization's activities and by the individual behaviour of the performers.

Safety culture is a manifestation of intangible categories (personal dedication to the cause, safety-oriented thinking, critical personal attitude, etc.). However, these intangible categories lead to tangible manifestations that can act as safety culture indicators that can be controlled, monitored, and measured.

Safety culture building and maintaining is provided through:

- the structure of management and control over personnel activity taking part in works (service rendering) at systems and equipment affecting safety;

- maintaining high level of personnel qualification taking part in works (service rendering).

Safety culture is being created and maintained through:

- recruiting and profession training of personnel involved in safety-related professional activities;

- strict compliance with discipline standards and clear delegation of authorities and personal responsibility of division heads and executive specialists;

- understanding by each employee of his/her impact over the safety and the consequences which non-compliance with regulations, duty requirements and technical rules as well badquality work may lead to;

- self-monitoring by employees of their activities which may affect safety;

- understanding by each division head or specialist that concealing errors is inadmissible and that it is important to reveal and eliminate their reasons, to constantly motivate personal growth, learn and adopt the world best practices;

- introduction of reward system for professional achievements that promotes openness among employees and does not welcome concealing of errors in their mistakes;

- lesson learning from previous errors and erroneous personnel actions.

Maintaining the qualifications of the organization's employees is the responsibility of both the managers and the employees themselves. Employees of the organization, including managers, should maintain their qualifications by studying relevant regulatory and technical documentation, exchanging information and experience at trainings, internships and seminars. 


\section{Conclusions}

\section{QAP for OIAE are divided into:}

1) general QAP, the action of which applies to all the work performed and the services provided that affect the safety of nuclear facilities at all stages of its life cycle;

2) private QAP organizations engaged in activities that affect the safety of nuclear facilities, at a separate stage of the life cycle of nuclear facilities and (or) in the implementation of the licensed activity in the field of atomic energy.

Organizational, technical, and other quality assurance measures contained in the QAP should be based on a differentiated approach that takes into account classifications of systems (elements) and facilities for nuclear facilities for their impact on the safety of nuclear facilities in accordance with federal regulations and rules for the use of atomic energy.

The main objectives of quality assurance:

- ensuring quality and timely performance of work;

- ensuring control over high-quality and timely performance of work.

The main methods of solving tasks:

- planning and systematic implementation of activities to ensure the required quality at all stages of production activities;

- a clear distribution of personal responsibility of managers and performers for the work performed;

- selection and provision of the required level of staff qualification in accordance with the requirements of job descriptions;

- building a culture of personnel safety;

- creation of an effective system for documenting work results and control;

- effective management of financial, logistical and human resources;

- conducting systematic internal audits (audits) of the requirements of the QAP and assess its effectiveness;

- management review of the implementation of the adopted policy in the field of quality assurance and its updating.

In order to achieve the goals of quality assurance, management is committed to:

- perform work at the nuclear power station in full compliance with the requirements of regulatory and technical documents;

- to create the necessary conditions for each employee to perform his or her duties with high quality and on time, using the accumulated experience, skill and knowledge;

- to carry out the allocation of the necessary financial, material and technical and human resources to carry out work in terms of quality assurance;

- periodically analyze the quality system to ensure that it constantly meets the accepted policy and is quite effective;

- perform the requirements of the QAP;

- to bring the adopted policy to all staff.

When operating a quality management system or a management system (hereinafter referred to as QMS) in an organization that develops a QAP, developed in accordance with the provisions of national and / or international standards, the QAP should contain brief information on the QMS (including its scope, information on the QMS requirements, its validity period, references to the documented QMS procedures used in the design and implementation of the QAP).

Description of the quality policy of the organization - the developer of the software development program, establishes:

1) the priority of ensuring the safety of nuclear facilities in the implementation of activities in the field of the use of atomic energy; 
2) the main objectives in the field of quality and methods for their achievement;

3) the commitment of the leadership of the organization-developer of the QAP in the field of quality.

This work was financially supported by Ministry of Science and Higher Education of the Russian Federation (\#NSh-3492.2018.8).

\section{References}

1. IAEA Safety Standard No. N GS-R-3 "Control System for Facilities and Activities"

2. IAEA Safety Standard No. GS-G-3.1 "Application of a facility and activity management system"

3. ISO 9001:2015 "Quality management systems - Requirements"

4. S.B. Sborshchikov, E.E. Bakhus, Industrial engineering, 12, 60-67 (2018)

5. S. Sborshikov, A. Bobin, MATEC Web of Conferences 27th R-S-P Seminar, Theoretical Foundation of Civil Engineering (27RSP) TFoCE, 04086 (2018)

6. A. Aleksanin, S. Sborshikov, IOP Conference Series: Materials Science and Engineering 21, Construction - The Formation of Living Environment, 062006 (2018)

7. S.B. Sborshchikov, P.A. Zhuravlev, E.E. Bakhus, Industrial engineering, 13, 76-79 (2018)

8. S.B. Sborshchikov, N.V. Lazareva, R.E. Vedenskij, E.E. Bakhus, Herald of Civil Engineers, 2, 269-275 (2018)

9. S.B. Sborshchikov, D.M. Leibman, Bulletin of the Belgorod State Technological University. V.G. Shukhov,1, 111-116 (2018)

10. S.B. Sborshchikov, D.M. Leibman, Bulletin of the Belgorod State Technological University. V.G. Shukhov, 2, 88-93 (2018)

11. S.B. Sborshchikov, D.M. Leibman, G.N. Shinkareva, L.A. Maslova, Bulletin MGSU, 11, 12, 1240-1247 (2017)

12. S.B. Sborshchikov, N.V. Lazareva, E.E. Bakhus, Bulletin of the Belgorod State Technological University. V.G. Shukhov, 12, 220-225 (2017)

13. S.B. Sborshchikov, N.V. Lazareva, E.E. Bakhus, Bulletin of the Belgorod State Technological University. V.G. Shukhov, 11, 186-190 (2017)

14. S.B. Sborshchikov, P.A. Zhuravlev, Bulletin of the Belgorod State Technological University. V.G. Shukhov, 7, 198-201 (2017)

15. S.B. Sborshchikov, G.N. Shinkareva, L.A. Maslova, Scientific Review, 14, 99-102 (2017)

16. A. Aleksanin, Bulletin of the Belgorod State Technological University. V.G. Shukhov, 7, 28-31 (2017)

17. A.A. Bobin, Estimated contract work in construction, 1, 46-49 (2016)

18. A. Aleksanin, S. Sborshikov, MATEC Web of Conferences 5"5th International Scientific Conference "Integration, Partnership and Innovation in Construction Science and Education", IPICSE 2016" 20, 05013 (2016)

19. S.B. Sborshchikov, D.M. Leibman, Scientific Review, 18, 191-195 (2016)

20. V.I. Telichenko, V.M. Roitman, Fires and emergencies: prevention, elimination, 1, 912 (2014) 